\title{
Research on English Translation Technologies from the Perspective of Cultural Exchange
}

\author{
Feifei Sun \\ Shaanxi Xueqian Normal University, Xi’an, 710061, China
}

Keywords: Translation technologies, Cultural exchange, Cultural communication

\begin{abstract}
Translation is the information transformation between two languages, which is also the cultural communication reflected by the two languages. In today's world, cultural exchanges are deepening, and English translation skills become the content that all the translators must study from the perspective of cultural exchange. Based on the comparative study of Chinese and English culture, this paper puts forward the strategies of English translation technologies and talents cultivation from the perspective of cultural exchange, which can provide some references for the relevant researchers.
\end{abstract}

\section{Introduction}

English and Chinese are in the process of development of different cultures, the expression habits also exist certain differences, these differences are not only reflected in the way of speaking, and language expression and other aspects. When China in intercultural communication with foreign countries, often due to language barriers caused by both the error phenomenon in the information exchange process, it is difficult for cross-cultural communication, is not conducive to Chinese in international development and growth. Therefore, how to effectively reduce language differences has become the main research object to promote cross-cultural communication. In the process of English translation, the translator must of each country's cultural background and language expression have a profound understanding, accumulation of translation skills in practice, thereby enhancing the level of translation the translator. Translation is the transformation of information between the two languages. It is also the cultural exchange and transformation reflected by the two languages. Therefore, it is more important to be familiar with the two cultures than to master the two languages. Translation is the bridge between two languages and cultures. The rich connotation of culture is communicated and communicated between the two languages through the bridge of translation. Cross cultural communication translation has the general nature of communication and communication, and transmits information. But the first priority is cultural communication. Translation is intercultural communication, and it is the communication and dissemination of culture. Two cultures and their differences to the translator only relates to the real interpretation of familiar language transfer information. Through the translation, the target language reader contacts with and understands the source language information and the culture, simultaneously also enriches the target language culture, realizes the cultural exchange. At this stage, in the process of showing social values and spreading the culture of various countries, English translation is not only necessary work, but also an effective way to improve Chinese social cognition and understand western culture.

\section{Translation Technologies from the Perspective of Cultural Exchange}

\subsection{Transform Technology of Part of Speech}

The conversion of parts of speech in English translation is mainly reflected in four aspects: noun conversion, verb conversion, adjective or adverb conversion, and preposition conversion. According to the habit of English grammar, there is only one predicate verb in each sentence, so the gerund and verb nominalization often occur. However, the use of verbs in the Chinese context will not be 
restricted by such factors. Many nouns in Chinese, such as shape, status, impression, can find their corresponding parts of speech in English. It is because of the two different grammatical environments of Chinese and English that the use of nouns often occurs in the use of English. Such as the use of to have a rest make no mention of, using mention, attention and attention using pay to, although the word is a noun, but in phrases expressing the meaning of the verb. On the basis of mastering the commonly used words, English translation must also master the considerable amount of professional vocabulary involved in the related fields, and have a very strong professional, involving a wide range of fields. In order to translate various documents accurately, translators must master the historical and cultural background and customs of the relevant countries and nations. English translation should also master and use the skills of English translation and the language features of English, so as to avoid the specialization of professional terms and lose the true meaning of professional terms. Therefore, in order to improve the quality of English translation, the translator must have good professional knowledge, understand and grasp the history of the world's cultural diversity and ethnic customs, and enhance the cross-cultural awareness, in order to increase the accuracy of the translation, in order to effectively promote the technical ability.

\subsection{Decrease or Increase Technology of Words}

In English translation, the more commonly used is the translation of the increase method. There are some differences between the two languages of English and Chinese in terms of language content and expression logic. A problem often encountered in the process of translation is that the meaning of a word in Chinese expression is clear logic, clear expression, but the translation into English would be a serious mistake or statement is illogical logic. In the process of English translation in the text not appropriate to add words or delete some form but not to repeat the meaning of lexical repetition, which makes the statement clear expression, clear logic, and the translation of the text more accurately. The Chinese nation is the representative of oriental culture. Oriental culture attaches great importance to the image thinking, while western countries pay more attention to the abstract thinking, the difference between eastern and Western cultures directly caused the English sentence translation will often appear deviation and dislocation. English sentence strong logic, the integrity of the sentence type, the person is very small, very seriously in the objective description of things, which we will often see a lot of passive sentences in English translation. In English translation, the translation of sentence patterns often appears deviation and dislocation, which greatly increases the difficulty of English translation. For example, in the translation of seeing is believing, if direct translation, the English sentence is simple single, but if using the method of processing translated into "it is better to see for oneself rather than to hear for many times" will not only make the semantic expression more clearly using conjunctions, but also conducive to the understanding of the west the meaning of the sentence. As for "Put the function of the accessories is in order to be able to make the dress look more in line with his temperament", there are three definite articles "the"'". The definite article in the process of translation we have to give up the translation of this is the function of jewelry in order to be able to make the dress look more in line with his temperament.

\subsection{Integration Technology of Different Cultures}

Translators should be able to fully understand the differences between Chinese and Western cultures when translating English from a cross-cultural perspective. Many translators often ignore the Chinese culture in order to make the translation conform to the logic of the west, which is also unfavorable to the translation effect. So only the integration of the two cultures, can make two kinds of cultural fusion in language translation, and find the equivalence of the source language, for some proper nouns, the translator can even integrate the two cultures created their own words. For example, the famous Tianjin go believe, if the literal translation of the "Dog ignore" in the west do not understand the enterprise culture on the basis of will never agree with this product, so in order to facilitate the understanding of trademark and the beauty of the west, translation using homophonic translation go believe. In Business English translation of international trade, also often encountered in English some words, but because of the history and culture of different words in the expression of 
difference has meaning, difficult to translate. For example, the dragon is the symbol of the Chinese national spirit, it means power, strength and good luck, the ancient emperor called sons of the heaven, descendants of the Chinese nation are called the dragon dragon to all the children of the Yellow Emperor translated into English is dragon, while Dragon said the terrorist monster and monster in English, is a derogatory term. In today's society is political multi polarization, economic globalization is the development of culture, diversified development, and these are in need of mutual communication and exchanges between countries can be achieved, the main means to realize the status quo is translation. Our understanding of western politics, economy and culture is accomplished through English translation, and therefore absorbs the advanced ideas of western developed countries, and promotes the rapid development of all aspects of our country. Thus, English translation of information transmission and communication function is significant, it is because of the English translation to encourage the international exchange of information more freely, can China's culture in the international spread and development. It is with English translation that economic globalization, political polarization and cultural diversity can be realized.

\section{Strategies of Talents Cultivation from the Perspective of Cultural Exchange}

\subsection{Promote Awareness of Cultural Difference}

As a universal language in the world, English plays a decisive role in the political and economic and cultural exchanges in the world. All the time, English is a major basic course in Chinese universities, which not only promotes the close communication between China and Western countries, but also lays a good foundation for the future development of talents in colleges and universities. However, due to the influence of the traditional examination oriented education concept, there are some problems such as poor flexibility, poor adaptability and poor cultural awareness in English education courses in Chinese universities. Based on this case, through the application of cross cultural education in college English curriculum can effectively fill the short board in English teaching, so as to further accelerate the pace of reform of English education in colleges and universities in our country, cultivate more high-quality talents for the society for applied English. The formation of translation ability is not accomplished overnight, but needs a long and complicated learning process. If we want to further improve the translation level of college students on the basis of existing, educators must actively carry out cultural interaction activities, so that students can actively participate in. However, in the course of college English translation practice, most of the students will focus on learning in the classroom teaching of theoretical knowledge, not only causes the cultural differences to conduct a comprehensive and in-depth study, but also did not pay attention to the basic problems in the process of translation. Based on this, the day after the translation course, educators should further improve students' awareness of cultural differences, to help them prepare long-term learning, combined with the learning situation of students to make the teaching plan to, for a short period of time to cultivate good habits of students thinking.

\subsection{Strengthen Infiltration of Translation Technologies}

Intercultural communication translation is an art. Translators have professional translation knowledge, sufficient knowledge base, and a certain depth of Chinese and Western languages and culture. The construction of culture in translation is the key to do the translation work in a cross-cultural context, translators must fully understand the difference, culture and mode of thinking of dialectical view of the cultural turn in translation and make good use of network learning platform, and strive to accurately convey the cultural connotation. Cultural schema translation is very important in cross-cultural communication, but it needs to follow the principles of cultural adaptation and cultural communication to show readers the cultural charm of the source language cultural schema. In the translation teaching of college English course, it can involve not only the professional knowledge in the English textbook, but also the accumulation of the existing knowledge, culture and knowledge background. Thus, college English education should focus on the teaching of English 
culture deeply, on the one hand according to the learning ability of students to develop interest in higher oral English listening and writing training activities, on the other hand also increase the elective course teaching of students' knowledge, further expand the coverage of. The only way to help college students' basic knowledge of English culture deeply imprinted in the mind, to be able to make their performance in the days after the translation training updates in handy, so as to improve college students' level of translation teaching. In Chinese literature, passive sentences generally have their own obvious features. But in English, they don't have these words. They usually rely on the suffix of verbs to do this work, so they are in the translation of passive sentences. We need to add some of the features of our language to express their original meaning.

\subsection{Increase Training of Translation Practice}

In our country the traditional college English Teaching in the classroom, teaching methods are cramming education for educators to use, through some simple language communication cannot cultivate high level translation talents. In order to completely break the limitations of traditional English classroom teaching, English educators in Colleges and universities should combine the actual needs of the talent market to develop a new model of translation talents training. In fact, the translation training in itself is a kind of language skills to help students transform teaching activities, so educators should focus on basic skills training in the teaching process, combining with the current situation of students' learning to choose the different style of training and training subjects, help students master the rules of translation in a subtle process. In the course of translation teaching, many students will have to complete the translation task often illogical and ungrammatical in feeling, this is mainly due to language and cultural differences between English and Chinese nationalities. In order to better solve this problem, educators should pay attention to the use of the subject, guide students to rationalize the use of passive sentences, so as to freely complete the switch between the two languages. The Chinese nation is the representative of Oriental culture, Oriental culture attaches great importance to the image thinking, while western countries pay more attention to the abstract thinking, the difference between eastern and Western cultures directly caused the English sentence translation will often appear deviation and dislocation. English sentences with logical integrity, attention to sentence, the person is very small, very seriously in the objective description of things, which we will often see a lot of passive sentences in English translation. The characteristics of Chinese sentences is the integrity of the information expression, pay attention to understanding and understanding. Only by constantly increasing the students' translation training can the students' translation level be improved.

\section{Conclusion}

English is the universal language of the world, so English translation bears the media of international cultural communication, the political multipolar and the important task of economic and global development. It also makes English translation must be carried out from the perspective of cross culture, only in the process of translation into the culture of the west, to make it more in line with the original, but also more conducive to our understanding of language, so that more accurate English translation, to promote the exchange of Chinese and western culture.

\section{References}

[1] Xiong Xiao, Zhu Dongjiang. CE Translation Studies and Practice from Cross-Culture Communication Perspective [J]. Journal of Hanjiang Normal University, 2017, 37(3): 77-83.

[2] Xu Mingwu, Liang Linxin. Flexible Aggression: Reception Strategies in C-E Translation for Global Communication of Culture [J]. Language and Translation, 2015(1): 58-63.

[3] Zhao Sijia. The Influence of Cultural Construction and Cultural Deficiency on English Translation Practice [J]. Education Teaching Forum, 2017(30): 75-76.

[4] Wen Jing. Culture Association and Communication in Translation Studies [J]. The Guide of Science \& Education, 2014(6): 206-207. 